\title{
Effect of high-energy heavy ion irradiation on the crystallization kinetics of Co-based metallic glasses
}

\author{
ROHIT JAIN, DEEPIKA BHANDARI, N S SAXENA*, S K SHARMA ${ }^{\dagger}$ and A TRIPATHI \\ Department of Physics, University of Rajasthan, Jaipur 302 004, India \\ ${ }^{\dagger}$ Department of Physics, Malaviya Regional Engineering College, Jaipur 302 017, India \\ ${ }^{\ddagger}$ Nuclear Science Centre, Aruna Asaf Ali Marg, New Delhi 110 067, India
}

MS received 5 September 2000; revised 18 October 2000

\begin{abstract}
Differential scanning calorimeter (DSC) is employed to study the crystallization kinetics of irradiated (at three different fluences with high-energy heavy ion; $\mathrm{Ni}^{11+}$ of $150 \mathrm{MeV}$ ) specimens of two Co-based metallic glasses. It is found that the crystallization process in both the glasses is completed in two phases. The DSC data have been analysed in terms of kinetic parameters viz. activation energy $\left(E_{c}\right)$, Avrami exponent $(n)$, dimensionality of growth $(m)$, using two different theoretical models. The results obtained have been compared with that of virgin samples. The lower activation energy in case of second crystallization occurring at higher temperature indicates the easier nucleation of second phase. The abnormally high value of Avrami exponent in Co-Ni glass indicates very high nucleation rate during first crystallization.
\end{abstract}

Keywords. Crystallization kinetics; high-energy heavy ion irradiation; morphology.

\section{Introduction}

The ion-beam assisted techniques have made substantial contributions as a selective tool for understanding, fabricating and characterization of amorphous alloys (Appleton et al 1985; Rauhala et al 1998). The effect of low energy heavy ion irradiation (up to $500 \mathrm{keV}$ ) on the crystallization kinetics of metallic glasses have been reported by Köster and Herold (1981) and Zhou et al (1994). The crystallization temperature is found to decrease significantly due to heavy ion irradiation at low energy. However, not much attention has been paid to investigate the effect of high-energy irradiation (more than $500 \mathrm{keV}$ ) on the stability against the crystallization of metallic glass. An ion penetrates a solid and slows down (i) by direct transfer of energy to nuclei by elastic collisions and (ii) by electronic excitation and ionization of atoms by inelastic collision. The two processes are known as nuclear energy loss, $S_{\mathrm{n}}$, and electronic energy loss, $S_{\mathrm{e}}$, respectively. At high energies (i.e. fast ions), the predominant mechanism for energy loss is electronic. When the radiation passes through the matter, it causes damage, which depends on the type and the energy of the radiation and the properties of the medium. It is generally pictured that atomic displacements are primarily induced by elastic collisions and not by electronic excitation or ionization. However, slowing down of heavy ions in insulator targets is known to induce structural changes called latent tracks.

\footnotetext{
*Author for correspondence
}

Now it has been established (Klaumunzer and Schumachar 1981; Mehta 1994) that electronic excitations can also provoke structural changes in materials. The understanding of the operative mechanisms, however, is quite incomplete. In view of this, an attempt has been made to investigate the effect of high-energy heavy-ion irradiation on the crystallization kinetics of two Co-based metallic glasses. For irradiation at different fluences, the $\mathrm{Ni}^{11+}$ ions of $150 \mathrm{MeV}$ have been used. The crystallization kinetics is the most convenient method as the sequence of phase during crystallization process provides the direction to see any structural changes due to irradiation. The crystallization process has been investigated using differential scanning calorimeter (DSC) under non-isothermal condition. The experimental data are analysed using two theoretical models developed by Kissinger (1956) and Gao and Wang (1986) in terms of kinetic parameters viz. activation energy, Avrami exponent and dimensionality of growth. The kinetic parameters obtained have been compared with that of virgin glasses.

\section{Experimental}

The multi-component metallic glasses viz. $\mathrm{Co}_{66} \mathrm{Si}_{16} \mathrm{~B}_{12} \mathrm{Fe}_{4} \mathrm{Mo}_{2}$ and $\mathrm{Co}_{66} \mathrm{Si}_{15} \mathrm{~B}_{14} \mathrm{Fe}_{4} \mathrm{Ni}_{1}$ (referred to as $\mathrm{Co}-\mathrm{Mo}$ and Co-Ni respectively hereafter) were cut in suitable size of $1 \times 1 \mathrm{~cm}^{2}$ for irradiation purpose. The specimens were cleaned ultrasonically and no thermal treatment was given to the samples prior to irradiation. The samples were stuck to the copper ladder for irradiation with the help of 
silver paint. The continuity of the samples was checked before putting the ladder in vacuum chamber. The samples were irradiated with $\mathrm{Ni}^{11+}$ ion beam of $150 \mathrm{MeV}$ energy at three different fluences ranging from $10^{11}$ to $10^{13}$ ions $/ \mathrm{cm}^{2}$ at the Nuclear Science Centre, New Delhi. The projected range for $150 \mathrm{MeV} \mathrm{Ni}{ }^{11+}$ ions was calculated using Trim program for both the glasses, indicating that probability of ion implantation is negligible. Only one irradiation geometry was used in this work, viz. the surface normal of the specimens was aligned parallel to the ion beam. The amorphous nature of all the irradiated and virgin samples was confirmed by $\mathrm{X}$-ray diffraction.

DSC study was performed on Rigaku $8230 \mathrm{~B}$ attached with thermal analysis station (TAS) to see the effect of irradiation on the crystallization kinetics of glass under non-isothermal condition. The samples were scanned from room temperature to $975 \mathrm{~K}$ in dry nitrogen flowing at $30 \mathrm{ml} / \mathrm{min}$ atmosphere at different heating rates: 5, 7, 10, 15 and $20 \mathrm{~K} / \mathrm{min}$. The instrument was calibrated prior to measurement using high purity standards of indium and lead with well known melting points and latent heat. The calibration and measurements of glasses were carried out under identical conditions for better accuracy.

\section{Results and discussion}

Figures 1 and 2 show the DSC traces of irradiated Co-Mo and $\mathrm{Co}-\mathrm{Ni}$ metallic glasses at three different fluences at a heating rate of $20 \mathrm{~K} / \mathrm{min}$. The DSC thermogram of virgin glasses at the same heating rate is also shown in the respective figures for comparison point of view. All the

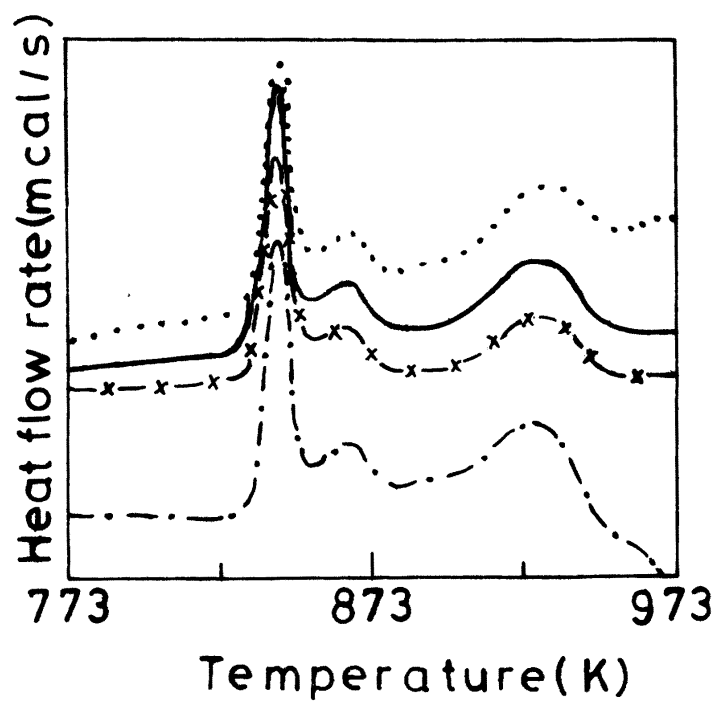

Figure 1. DSC thermograms of virgin and irradiated Co-Mo glass at the heating rate of $20 \mathrm{~K} / \mathrm{min}$ (- Virgin; $-\times-\times-\times-$ irradiated at fluence $1 \times 10^{11} \mathrm{ions} / \mathrm{cm}^{2} ;-\bullet-\bullet-\bullet-$ irradiated at fluence $1 \times 10^{12} \mathrm{ions} / \mathrm{cm}^{2} ; \quad \cdots \quad$ irradiated at fluence $1 \times 10^{13}$ ions $/ \mathrm{cm}^{2}$ ). thermograms (for virgin as well as irradiated samples) have well defined exothermic peaks indicating the occurrence of crystallization. However, in these glasses the crystallization is incomplete in a single stage. The Co-Mo glass exhibits two overlapping peaks of crystallization along with a small shoulder in the first peak at higher temperature side. This shoulder is clearly observed at relatively higher heating rates. The shoulder found on the higher temperature side of the main peak does not indicate the presence of any new phase, rather it is a manifestation of the delayed crystallization of the small portion of the glass that was adjacent to the wheel during spinning and hence experienced the most rapid cooling. As a result of the high quench rate, this part of the ribbon has much fewer (or no) quenched-in nuclei, and so crystallizes at relatively higher temperature. A similar type of shoulder has also been found in many other glasses e.g. $\mathrm{Fe}_{80} \mathrm{~B}_{20}$ (Greer 1982), $\mathrm{Al}_{75} \mathrm{Cu}_{15} \mathrm{~V}_{10}$ (Holzer and Kelton 1991) and $\mathrm{Ni}_{72} \mathrm{Mo}_{2} \mathrm{Co}_{6} \mathrm{~B}_{20}$ (Graydon et al 1995). It was reported that the shoulder found for $\mathrm{Fe}_{80} \mathrm{~B}_{20}$ glass was due to delayed crystallization for the $10 \%$ of the ribbon nearest to the wheel, and, when crystallized, this portion showed the identical phases as were found in the bulk of the glass (Greer 1982). The delayed crystallization is ascribed to the necessity to first develop nuclei in the rapidly cooled zone. On the other hand, the $\mathrm{Co}-\mathrm{Ni}$ glass has two peaks separated by wide temperature interval. In $\mathrm{Co}-\mathrm{Ni}$ glass, the second peak is not very clearly distinguished in DSC trace as the first and second peaks differ too much in magnitude. Figure 3 is given as a representative curve for the second peak with the stretched heat flow axis at the heating rate of $20 \mathrm{~K} / \mathrm{min}$. The first peak in both the glasses indicate hcp Co-solid solution while the second

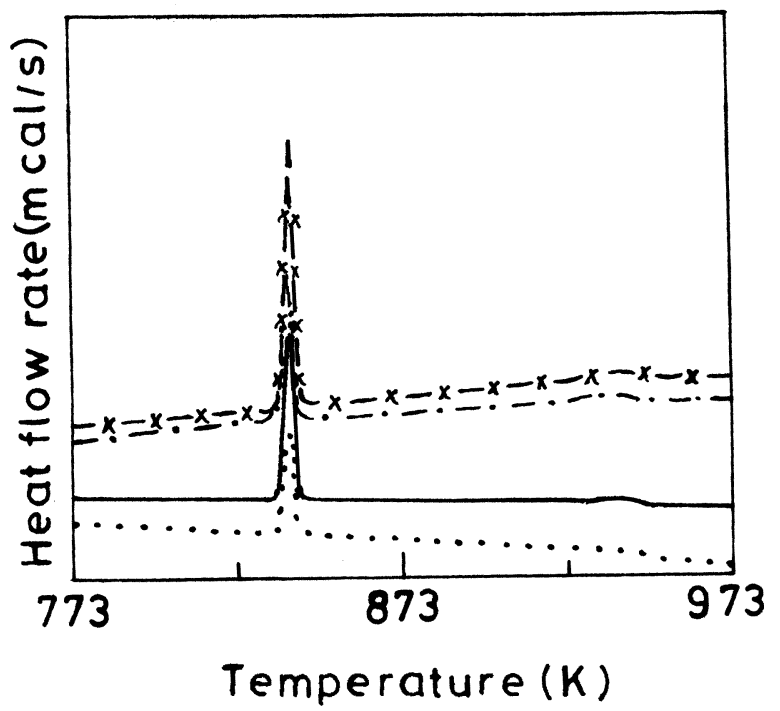

Figure 2. DSC thermograms of virgin and irradiated $\mathrm{Co}-\mathrm{Ni}$ glass at the heating rate of $20 \mathrm{~K} / \mathrm{min}$ (- Virgin; $-\times-\times-\times-$ irradiated at fluence $1 \times 10^{11}$ ions $/ \mathrm{cm}^{2} ;-\bullet-\bullet-\bullet_{-}$irradiated at fluence $1 \times 10^{12}$ ions $/ \mathrm{cm}^{2} ; \cdots$ irradiated at fluence $1 \times 10^{13}$ ions $/ \mathrm{cm}^{2}$ ). 


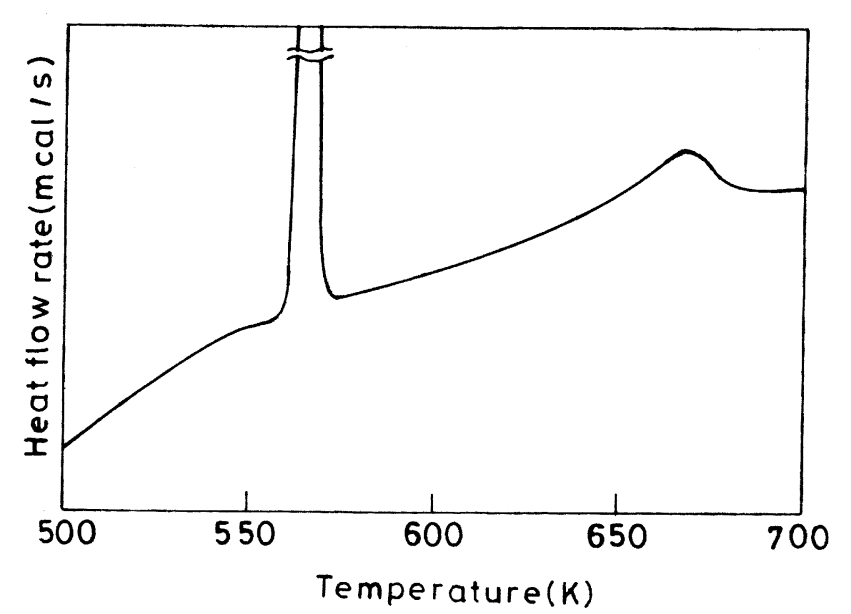

Figure 3. DSC trace of Co-Ni glass at the heating rate of $20 \mathrm{~K} / \mathrm{min}$ as a representative curve for showing the difference in magnitude of the two peaks of crystallization.

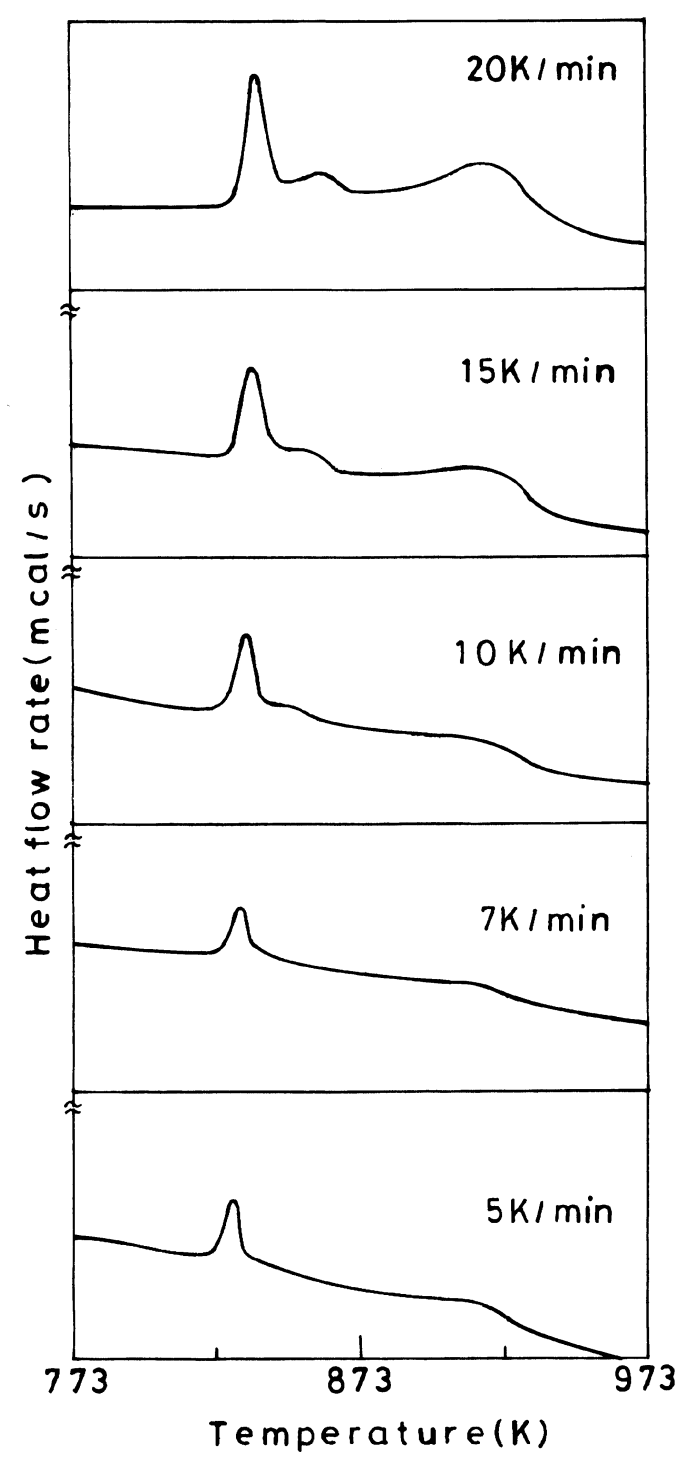

Figure 4. DSC thermograms of irradiated Co-Mo glass at the heating rate of $5 \mathrm{~K} / \mathrm{min}, 7 \mathrm{~K} / \mathrm{min}, 10 \mathrm{~K} / \mathrm{min}, 15 \mathrm{~K} / \mathrm{min}$ and $20 \mathrm{~K} / \mathrm{min}$ (fluence: $1 \times 10^{13} \mathrm{ions} / \mathrm{cm}^{2}$ ). peak shows body centred tetragonal (b.c.t.) $\mathrm{Co}_{3} \mathrm{~B}$ phase (Wang and Meng 1983).

Further, it is clear from the figures that there is no substantial change in the crystallization temperatures $\left(T_{\mathrm{c}}\right)$ and peak crystallization temperatures $\left(T_{\mathrm{p}}\right)$ after the highenergy heavy ion irradiation at different fluences ranging from $10^{11}$ to $10^{13}$ ions $/ \mathrm{cm}^{2}$. Similar observations have also been noticed at other heating rates. The DSC thermograms of one irradiated specimen (fluence: $1 \times 10^{13}$ ions/ $\mathrm{cm}^{2}$ ) from each glass at all the heating rates employed here are shown in figures 4 and 5 as representative curves.

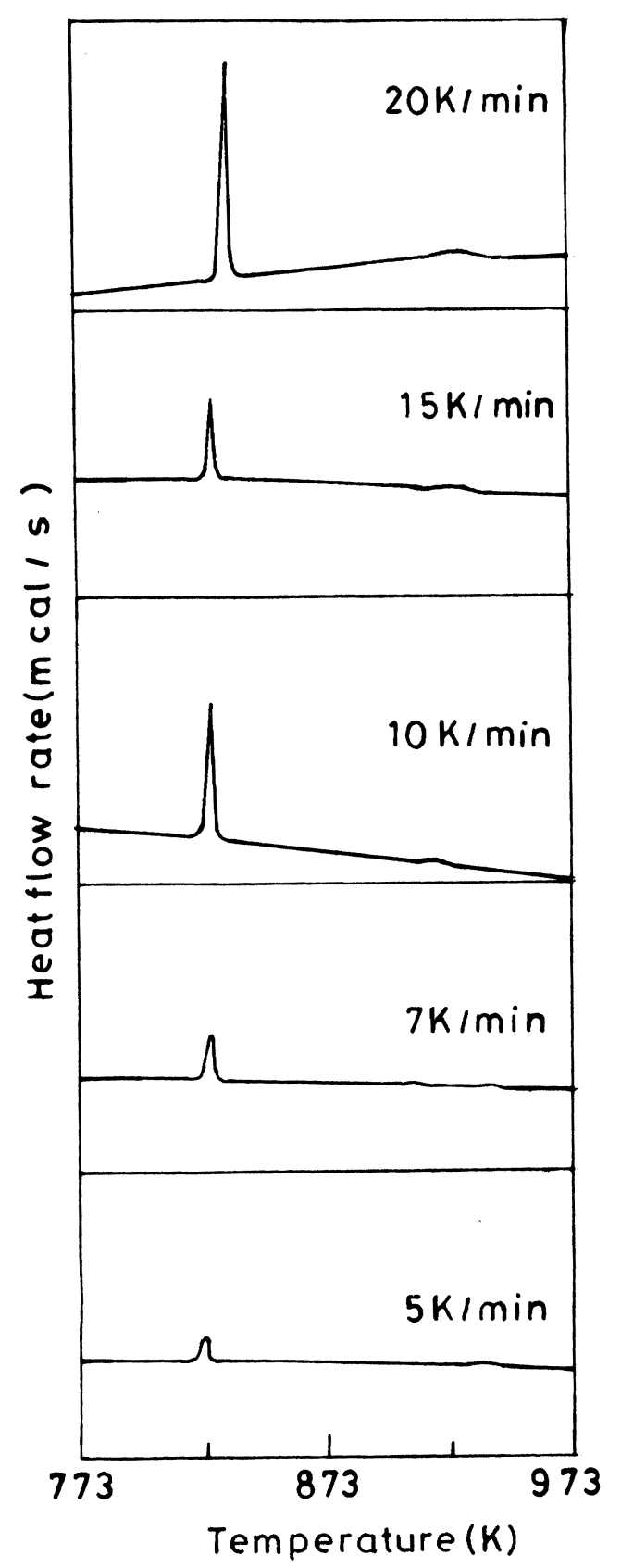

Figure 5. DSC thermograms of irradiated $\mathrm{Co}-\mathrm{Ni}$ glass at the heating rate of $5 \mathrm{~K} / \mathrm{min}, 7 \mathrm{~K} / \mathrm{min}, 10 \mathrm{~K} / \mathrm{min}, 15 \mathrm{~K} / \mathrm{min}$ and $20 \mathrm{~K} / \mathrm{min}$ (fluence: $1 \times 10^{13} \mathrm{ions} / \mathrm{cm}^{2}$ ). 
Table 1. Variation of crystallization temperatures with heating rate and different nature of the $\mathrm{Co}_{66} \mathrm{Si}_{16} \mathrm{Fe}_{4} \mathrm{~B}_{12} \mathrm{Mo}_{2}$ glass.

\begin{tabular}{|c|c|c|c|c|c|}
\hline \multirow[b]{2}{*}{ Sample } & \multirow{2}{*}{$\begin{array}{l}\text { Heating } \\
\text { rate } \\
(\mathrm{K} / \mathrm{min})\end{array}$} & \multicolumn{2}{|c|}{$\begin{array}{l}\text { Crystallization } \\
\text { temperature }\end{array}$} & \multicolumn{2}{|c|}{$\begin{array}{l}\text { Peak crystallization } \\
\text { temperature }\end{array}$} \\
\hline & & $T_{\mathrm{c} 1}(\mathrm{~K})$ & $T_{\mathrm{c} 2}(\mathrm{~K})$ & $T_{\mathrm{p} 1}(\mathrm{~K})$ & $T_{\mathrm{p} 2}(\mathrm{~K})$ \\
\hline \multirow[t]{5}{*}{ Virgin } & 5 & 819 & 877 & 829 & 908 \\
\hline & 7 & 821 & 888 & 832 & 913 \\
\hline & 10 & 825 & 894 & 837 & 920 \\
\hline & 15 & 828 & 897 & 838 & 926 \\
\hline & 20 & 830 & 898 & 841 & 928 \\
\hline \multirow{5}{*}{$\begin{array}{l}\text { Irradiated } \\
\text { (fluence } 1 \times 10^{11} \text { ions } / \mathrm{cm}^{2} \text { ) }\end{array}$} & 5 & 819 & 877 & 828 & 908 \\
\hline & 7 & 821 & 887 & 832 & 913 \\
\hline & 10 & 825 & 894 & 837 & 919 \\
\hline & 15 & 827 & 896 & 838 & 925 \\
\hline & 20 & 830 & 897 & 841 & 928 \\
\hline \multirow{5}{*}{$\begin{array}{l}\text { Irradiated } \\
\text { (fluence } 1 \times 10^{12} \text { ions } / \mathrm{cm}^{2} \text { ) }\end{array}$} & 5 & 819 & 877 & 828 & 908 \\
\hline & 7 & 821 & 887 & 831 & 913 \\
\hline & 10 & 825 & 894 & 837 & 920 \\
\hline & 15 & 827 & 896 & 838 & 925 \\
\hline & 20 & 830 & 898 & 841 & 928 \\
\hline \multirow{5}{*}{$\begin{array}{l}\text { Irradiated } \\
\text { (fluence } 1 \times 10^{13} \text { ions } / \mathrm{cm}^{2} \text { ) }\end{array}$} & 5 & 819 & 877 & 828 & 908 \\
\hline & 7 & 820 & 887 & 832 & 913 \\
\hline & 10 & 825 & 894 & 837 & 920 \\
\hline & 15 & 827 & 896 & 839 & 926 \\
\hline & 20 & 830 & 898 & 841 & 928 \\
\hline
\end{tabular}

Table 2. Variation of crystallization temperatures with heating rate and different nature of the $\mathrm{Co}_{66} \mathrm{Si}_{15} \mathrm{Fe}_{4} \mathrm{~B}_{14} \mathrm{Ni}_{1}$ glass.

\begin{tabular}{|c|c|c|c|c|c|}
\hline \multirow[b]{2}{*}{ Sample } & \multirow{2}{*}{$\begin{array}{c}\text { Heating } \\
\text { rate } \\
(\mathrm{K} / \mathrm{min})\end{array}$} & \multicolumn{2}{|c|}{$\begin{array}{l}\text { Crystallization } \\
\text { temperature }\end{array}$} & \multicolumn{2}{|c|}{$\begin{array}{l}\text { Peak crystallization } \\
\text { temperature }\end{array}$} \\
\hline & & $T_{\mathrm{c} 1}(\mathrm{~K})$ & $T_{\mathrm{c} 2}(\mathrm{~K})$ & $T_{\mathrm{p} 1}(\mathrm{~K})$ & $T_{\mathrm{p} 2}(\mathrm{~K})$ \\
\hline \multirow[t]{5}{*}{ Virgin } & 5 & 820 & 897 & 823 & 918 \\
\hline & 7 & 824 & 905 & 827 & 924 \\
\hline & 10 & 828 & 908 & 831 & 931 \\
\hline & 15 & 831 & 911 & 836 & 935 \\
\hline & 20 & 836 & 918 & 839 & 937 \\
\hline \multirow{5}{*}{$\begin{array}{l}\text { Irradiated } \\
\text { (fluence } 1 \times 10^{11} \text { ions } / \mathrm{cm}^{2} \text { ) }\end{array}$} & 5 & 820 & 897 & 823 & 918 \\
\hline & 7 & 824 & 905 & 827 & 924 \\
\hline & 10 & 828 & 907 & 831 & 932 \\
\hline & 15 & 830 & 911 & 836 & 936 \\
\hline & 20 & 836 & 917 & 839 & 938 \\
\hline \multirow{5}{*}{$\begin{array}{l}\text { Irradiated } \\
\text { (fluence } 1 \times 10^{12} \text { ions } / \mathrm{cm}^{2} \text { ) }\end{array}$} & 5 & 820 & 897 & 823 & 918 \\
\hline & 7 & 824 & 905 & 827 & 924 \\
\hline & 10 & 828 & 907 & 831 & 931 \\
\hline & 15 & 831 & 911 & 836 & 935 \\
\hline & 20 & 835 & 918 & 839 & 937 \\
\hline \multirow{5}{*}{$\begin{array}{l}\text { Irradiated } \\
\text { (fluence } 1 \times 10^{13} \text { ions } / \mathrm{cm}^{2} \text { ) }\end{array}$} & 5 & 820 & 896 & 823 & 918 \\
\hline & 7 & 824 & 905 & 827 & 925 \\
\hline & 10 & 828 & 908 & 831 & 931 \\
\hline & 15 & 831 & 910 & 836 & 935 \\
\hline & 20 & 836 & 918 & 839 & 938 \\
\hline
\end{tabular}


The $T_{\mathrm{c}}$ and $T_{\mathrm{p}}$ values of both the glasses (irradiated alongwith virgin specimens) have been listed in tables 1 and 2. The above observation may be explained by the fact that the high-energy heavy ions passing through solids lose most of their energy through the electronic excitations (ionization) of target atom. The immediate consequences of electronic excitations are atomic rearrangements under certain conditions. Atomic displacements induced by electronic excitations were identified and established by Klaumunzer and Schumacher (1981) and Hou Ming-dou et al (1990) by observing radiationinduced growth in metallic glasses. However, no new phase has formed during high-energy heavy ion irradiation. It seems that whatever defects produced due to the irradiation are recovered at temperatures well below those necessary to induce crystallization during heat treatment given to the system.

Further, to gain more information about the kinetics of crystallization of irradiated samples in terms of kinetic parameters viz. activation energy, Avrami exponent and

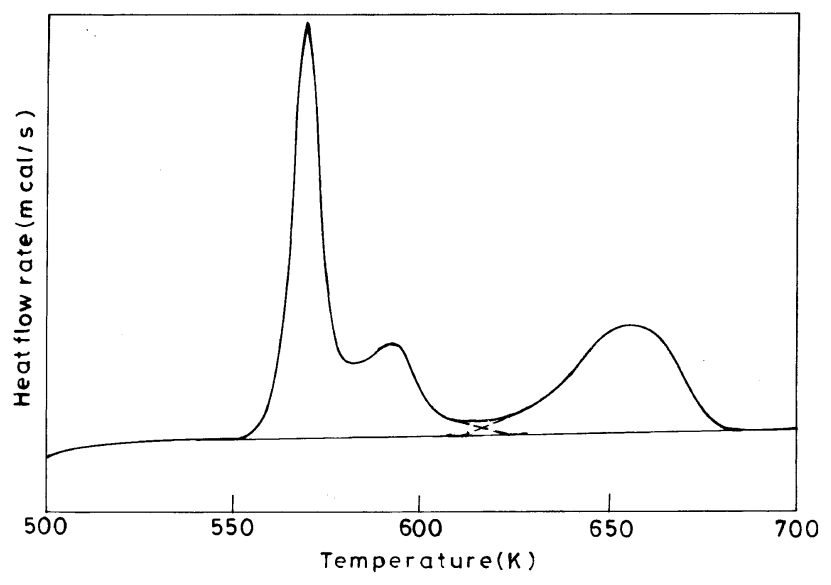

Figure 6. DSC trace of Co-Mo glass at the heating rate of $20 \mathrm{~K} / \mathrm{min}$ as a representative curve for showing the partition of two overlapping peaks of crystallization by systematic extrapolation. dimensionality of growth etc, the two theoretical models given by Kissinger (1956) and Gao and Wang (1986) have been used.

The Kissinger equation is given by

$$
\ln \left(\alpha / T_{\mathrm{p}}^{2}\right)=-E_{\mathrm{c}} / R T_{\mathrm{p}}+\text { constant, }
$$

where $\alpha$ is the heating rate, $T_{\mathrm{p}}$ the peak crystallization temperature. The plot of $\ln \left(\alpha / T_{\mathrm{p}}^{2}\right)$ vs $1000 / T_{\mathrm{p}}$ yields a straight line and the slope of this straight line gives the activation energy, $E_{\mathrm{c}}$.

Further, using the Gao and Wang model, the details of the kinetics of crystallization have been obtained through the determination of other parameters along with activation energy. The model gives a linear relationship between $\ln (\mathrm{d} X / \mathrm{d} t)_{\mathrm{p}}$ and $1000 / T_{\mathrm{p}}$, and is given by

$$
\ln (\mathrm{d} X / \mathrm{d} t)_{\mathrm{p}}=-E_{\mathrm{c}} / R T_{\mathrm{p}}+\text { constant, }
$$

where, $(\mathrm{d} X / \mathrm{d} t)_{\mathrm{p}}$ is the rate of transformed volume fraction at the peak of crystallization, $T_{\mathrm{p}}$ the peak crystallization temperature, $E_{\mathrm{c}}$ the activation energy and $R$ the gas constant. $E_{\mathrm{c}}$ is determined from the slope of the straight-line plot of the above equation. As mentioned earlier, the two exothermic events at all the heating rates, in Co-Mo glass overlap each other to some extent. The first transformation is not fully completed before the second one begins.

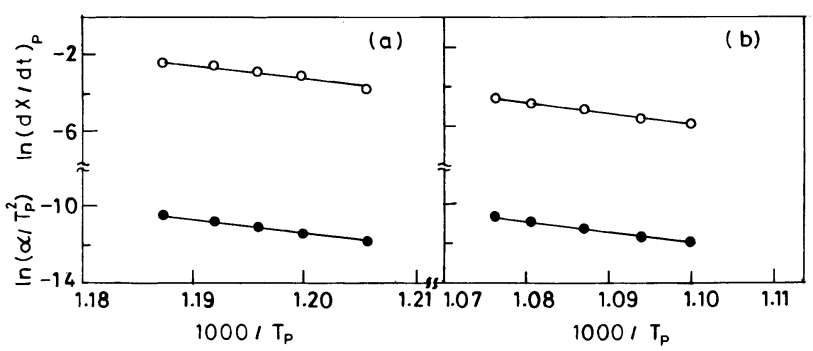

Figure 7. Kissinger's (๑) and Gao-Wang (o) plots for irradiated Co-Mo glass (fluence: $1 \times 10^{13} \mathrm{ions} / \mathrm{cm}^{2}$ ): (a) for first crystallization and (b) second crystallization.

\begin{tabular}{|c|c|c|c|c|c|c|}
\hline \multirow[b]{3}{*}{ Compositions } & \multicolumn{4}{|c|}{ Activation energy $(\mathrm{kJ} / \mathrm{mole})$} & & \\
\hline & \multicolumn{2}{|c|}{ Kissinger eq. } & \multicolumn{2}{|c|}{ Gao-Wang eq. } & \multicolumn{2}{|c|}{ Avrami exponent } \\
\hline & I peak & II peak & I peak & II peak & I peak & II peak \\
\hline $\begin{array}{l}\mathrm{Co}_{66} \mathrm{Si}_{16} \mathrm{Fe}_{4} \mathrm{~B}_{12} \mathrm{Mo}_{2} \\
\text { a. Irradiated } \\
\quad \text { (fluence } 1 \times 10^{13} \text { ions } / \mathrm{cm}^{2} \text { ) }\end{array}$ & $632 \pm 7$ & $465 \pm 7$ & $627 \pm 10$ & $446 \pm 10$ & 2 & 1 \\
\hline b. Virgin sample & $655 \pm 7$ & $459 \pm 5$ & $648 \pm 10$ & $459 \pm 10$ & 2 & 1 \\
\hline $\begin{array}{l}\mathrm{Co}_{66} \mathrm{Si}_{15} \mathrm{Fe}_{4} \mathrm{~B}_{14} \mathrm{Ni}_{1} \\
\text { a. Irradiated } \\
\quad \text { (fluence } 1 \times 10^{13} \text { ions } / \mathrm{cm}^{2} \text { ) }\end{array}$ & $508 \pm 7$ & $469 \pm 7$ & $493 \pm 10$ & $458 \pm 10$ & 9 & 2 \\
\hline b. Virgin samples & $506 \pm 7$ & $472 \pm 5$ & $491 \pm 10$ & $460 \pm 10$ & 9 & 2 \\
\hline
\end{tabular}

Table 3. Activation energy of crystallization of glasses. 
Further, the second phase has not begun to form at $T_{\mathrm{p} 1 \text {, }}$ peak crystallization temperature for the first transformation and similarly, the first transformation is completed prior to $T_{\mathrm{p} 2}$, peak crystallization temperature of the second transformation. Thus, the crystallization curve has been divided into two parts by systematic extrapolation of the two peaks for the calculation of rate of transformed volume fraction as shown in figure 6 . The small peak (shoulder) due to delayed crystallization $(\leq 5 \%$ of the main peak) is included in the main peak. In the case of Co-Ni glass no such problem occurs since the peaks are separated by wide temperature interval.

Kissinger and Gao-Wang plots of irradiated specimens are given in figures 7 and 8 for Co-Mo and Co-Ni glass, respectively. The activation energies computed from the slopes of straight lines are reported in table 3 . The $E_{\mathrm{c}}$ values of both the virgin glasses (Jain et al 2000) are also given in the same table. It can be noted from the table that there is no remarkable difference in the activation energy for both stages of crystallization for irradiated and virgin samples. The observed difference in the $E_{\mathrm{c}}$ values is due to small changes in $T_{\mathrm{p}}$ values of virgin and irradiated samples. Even a difference of the order of 0.2-0.4 K ( $<1 \mathrm{~K})$ in $T_{\mathrm{p}}$ values brings an appreciable change in $E_{\mathrm{c}}$ values (of the order of $\pm 25 \mathrm{~kJ} / \mathrm{mole}$ ). Further, the activation energy for second crystallization in both the specimens is lower than that of first crystallization, which indicates an increase of driving force for second crystallization i.e. easier nucleation for the $\mathrm{Co}_{3} \mathrm{~B}$ b.c.t. phase. The difference in the values of activation energy computed through the two models may be attributed to basic assumptions lying in the two theories discussed elsewhere (Jain et al 2001).

In addition to activation energy, the variation of transformed volume fraction with temperature during both crystallization stages for both the glasses at the heating rate of $10 \mathrm{~K} / \mathrm{min}$ has been shown in figures 9 and 10 . It is evident from the figures that the percentage of transformed volume fraction during crystallization is exactly same for all the irradiated and virgin specimens. Thus, the above result ensures the same activation energy of all the specimens as the rate of crystallized volume fraction is same in virgin and irradiated specimens.

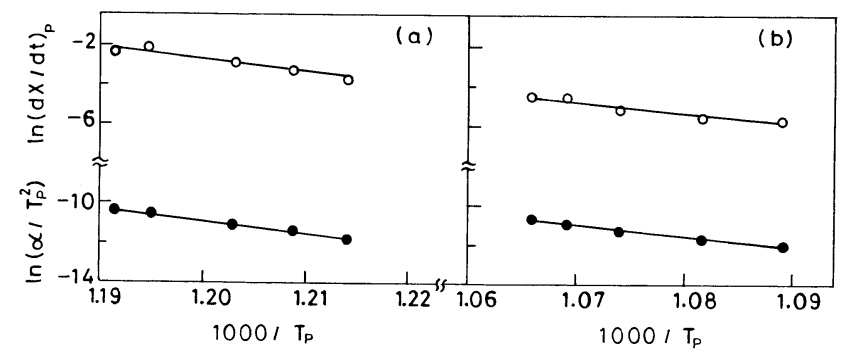

Figure 8. Kissinger's (•) and Gao-Wang (o) plots for irradiated Co-Ni glass (fluence: $1 \times 10^{13}$ ions $/ \mathrm{cm}^{2}$ ): (a) for first crystallization and (b) second crystallization.
To obtain the information about morphology of growth and Avrami exponent, the following relations from GaoWang model have been used

$$
\begin{aligned}
& K=K_{0} \exp \left(-E_{\mathrm{c}} / R T\right), \\
& K_{\mathrm{p}}=\alpha E_{\mathrm{c}} / R T_{\mathrm{p}}^{2}, \\
& (\mathrm{~d} X / \mathrm{d} t)_{\mathrm{p}}=0.37 n K_{\mathrm{p}},
\end{aligned}
$$

where $n$ is Avrami exponent, $K_{\mathrm{p}}$ the reaction rate factor, $K_{0}$ the frequency factor and other symbols have their usual meanings. In the case of Co-Mo glass, the average value of $n$ comes out to be 2 and 1 for first and second crystallization stages, respectively. The $n$ values for both the crystallization stages indicate one-dimensional growth along with surface crystallization. On the other hand, in Co-Ni glass, for first crystallization stage, the average value of $n$ comes out to be $\sim 9$ while it decreases to 2 in case of second crystallization. The $n$ value for first stage of crystallization indicates very high nucleation rate with three-dimensional growth while crystals grow in one dimension during the second crystallization. The values of $n$ verify fast crystallization of first phase as compared to the second one; the temperature duration is very short in

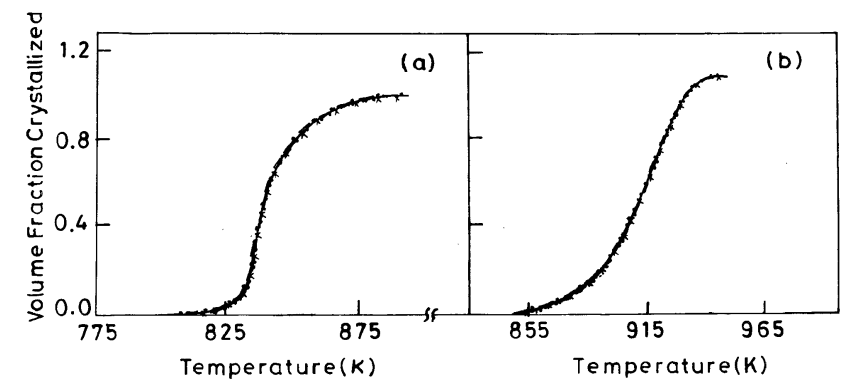

Figure 9. Volume fraction transformed as a function of temperature for $\mathrm{Co}-\mathrm{Mo}$ glass at a heating rate of $10 \mathrm{~K} / \mathrm{min}$. (a) first crystallization and (b) second crystallization (- Virgin; $-x-x-x-$ irradiated at fluence $1 \times 10^{11} \mathrm{ions} / \mathrm{cm}^{2} ;-\bullet-\bullet-\bullet-$ irradiated at fluence $1 \times 10^{12} \mathrm{ions} / \mathrm{cm}^{2} ; \cdots$ irradiated at fluence $1 \times 10^{13}$ ions $/ \mathrm{cm}^{2}$ ).

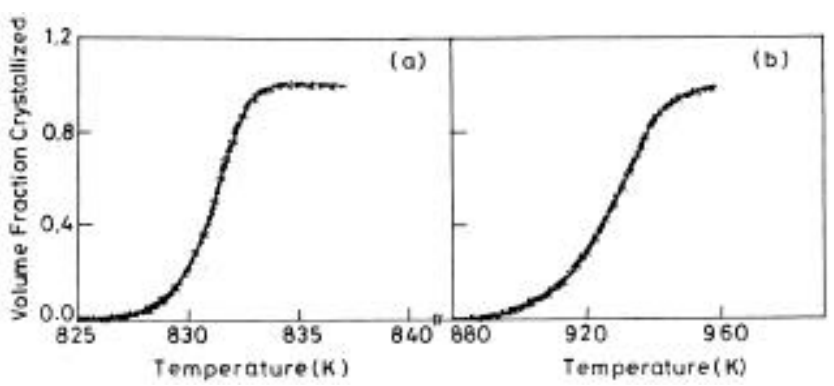

Figure 10. Volume fraction transformed as a function of temperature for $\mathrm{Co}-\mathrm{Ni}$ glass at a heating rate of $10 \mathrm{~K} / \mathrm{min}$. (a) first crystallization and (b) second crystallization (- Virgin; $-x-x-x-$ irradiated at fluence $1 \times 10^{11}$ ions $/ \mathrm{cm}^{2} ;-\bullet-\bullet-\bullet-$ irradiated at fluence $1 \times 10^{12} \mathrm{ions} / \mathrm{cm}^{2} ; \cdots$ irradiated at fluence $1 \times 10^{13}$ ions $/ \mathrm{cm}^{2}$ ). 
the case of first crystallization as compared to the second one. The values of $n$ for both glasses (irradiated and virgin) are listed in table 3 . It is clear from the table that after irradiation, there is no change in the Avrami exponent, hence the morphology of growth does not change. The reason behind this may be again the recovery of defects during the heat treatment given to the system. The results of specimens irradiated at different fluences also agree with the results of present irradiated sample.

The above results suggest that irradiation of $\mathrm{Ni}^{11+}$ ions with the energy of $150 \mathrm{MeV}$ at different fluences ranging from $10^{11}$ to $10^{13}$ ions $/ \mathrm{cm}^{2}$ do not affect the thermal stability against crystallization of Co-based metallic glasses in any way. The irradiation of further high energy (up to few $\mathrm{GeV}$ ) may have some influence on the devitrification kinetics of these glasses. The attempts are going on in this direction.

\section{Conclusions}

The present study, dealing with effect of irradiation of fluences ranging from $10^{11}$ to $10^{13}$ ions $/ \mathrm{cm}^{2}$ on crystallization kinetics of Co-based glasses, reveals that, systems possibly with different atomic arrangements due to highenergy heavy ion irradiation, crystallize into same phase, even at same temperature. The high-energy heavy ion irradiation does not bring any discernible change in the crystallization kinetics. The defects due to irradiation are recovered well below the temperature necessary for crystallization during the thermal treatment given to the system. Both the glasses crystallize into two phases. The large value of Avrami exponent during first crystallization in Co-Ni glass shows a very high nucleation rate with three-dimensional growth.

\section{Acknowledgement}

Authors are thankful to Prof. G K Mehta, Nuclear Science Centre, New Delhi, for facilities.

\section{References}

Appleton B L, Sartwell B, Peercy P S, Schaefer R and Osgood R 1985 Mater. Sci. \& Engg. 7023

Gao Y Q and Wang W 1986 J. Non-Cryst. Solids 87129

Graydon J W, Thorpe S J and Kirk D W 1995 Acta Metall. Mater. 431363

Greer A L 1982 Acta Metall. 30171

Holzer J C and Kelton K F 1991 Acta Metall. Mater. 391833

Hou Ming-dou, Klaumunzer S and Schmacher G 1990 Phys. Rev. B41 1144

Jain Rohit, Bhandari Deepika, Saxena N S and Sharma S K 2000 J. Thermal Anal. (communicated)

Jain Rohit, Saxena N S, Bhandari Deepika and Sharma S K 2001 Mater. Sci. \& Engg. A298 51

Kissinger H E 1956 J. Res. NBS 57217

Klaumunzer S and Schumacher G 1981 Phys. Rev. Lett. 511987

Köster U and Herold U 1981 Glassy metals I (ed.) H Beck and H J Guntherodt (Berlin: Springer-Verlag) p. 25 and references therein

Mehta G K 1994 Phys. Education 11245

Rauhala E, Ahlgren T, Vakevainen K, Raisanen J and Keinonen 1998 J. Appl. Phys. 83738

Wang Yuming and Chaofu Meng 1983 J. Non-Cryst. Solids 54 187

Zhou Fie, He Kai-Yuan and Man Ling-Su 1994 Mater. Sci. \& Engg. A181/182 1419 